\title{
Environmental Factors of Knowledge Management Model for Implementation and Adoptation in the Construction Industry
}

\author{
Katun M. Idris \\ Faculty of Built Environment, \\ Department of Quantity Surveying, \\ Universiti Teknologi Malaysia, Johor, Malaysia \\ E-mail: idriskt@gmail.com
}

Kolawole A. Richard

Faculty of Environmental Science,

Department of Environmental Planning and Management,

Kenyatta University, Nairobi, Kenya

\author{
Abdullahi Y. Waziri \\ Faculty of Built Environment, \\ Department of Quantity Surveying, \\ Universiti Teknologi Malaysia, Johor, Malaysia
}

Received: October 31, 2015 Accepted: December 28, 2015 Published: January 4, 2016

doi:10.5296/jsss.v3i1.8509

URL: http://dx.doi.org/10.5296/jsss.v3i1.8509

\begin{abstract}
This paper presents a knowledge management (KM) environmental factor model that encompasses a set of the hypothesized model for KM environmental factor and measurement models for adaptation and application. Two hundred and fourty five questionnaire surveys were administered for the research. The hypothesized model of KM environmental factor was
\end{abstract}


tested using structural equation modeling approach with a proposed model developed. Five constructs of KM environmental factors were considered and analyzed; culture, strategy, organization information, management leadership, and rules/regulation with their reliability and Cronbach's Alpha coefficient of 0.82, 0.919, 0.85, 0.79, and 0.86 respectively. Similarly, all fit indices and factor loadings were significant leading to a prudent model attainment. The study offers a foundation for understanding some modest predisposition of the industry as it enters KM. Construction industry and researchers can adopt the model to serve as a guide for adoption and implementation

Keywords: Construction industry, Knowledge management (KM), Environmental factors

\section{Introduction}

Implementation of knowledge management $(\mathrm{KM})$ in the construction industry has been a concern in some developing countries, as it is an answer to an upward improvement of their organization practices and professions. In today's construction business, the profit margin is becoming hard to achieve, projects are becoming more complex and competitiveness has become the order of the day (Surakratanasakul \& Hamamoto, 2014). Management of knowledge in the construction industry is placing a crucial role for business effectiveness to convert business opportunities into a viable gain (Valmohammadi et al., 2015). Thus, the essentials aim of the construction industry is been driven from capital concentration to knowledge concentration (Tong et al., 2015). In the awareness economy, knowledge has been transformed not only to a strategic asset, but one of the important organizational assets (Ahern et al., 2014). KM in the construction organization is about making use of available organizational resources (knowledge) to accomplish its organizational objectives (Amini et al., 2014).

However, $\mathrm{KM}$ in the construction organization is seen as a way of determining and influencing individual learning, ideas, own skills and best practices (Balaid et al., 2014). Bosch-Sijtsema and Henriksson (2014) on the other hand, argue that learning, skill and ideas associated with passed project's acheivement and disappointments, services, customers and product are resources that can yield more durable, maintainable modest advantage for the construction organization. Construction organization can improve their organization vision and wisdom through proper management of worker's knowledge and organizational learning; tactical inventions and improvement can also be enhanced (Egbu, 2004). KM is a proficient way to advance the humble recompenses of organizational skill, ideas and learning at more reasonable cost, time, quality and client satisfaction (Alekseev, 2010). The construction organization needed KM to advance self-effacing benefit through enhancement of technology, values, effectiveness of project delivery, good relationships with colleagues, friends and clients (Al-Gahtani \& Ghani, 2010). The organization is fast developing and facing a lot of challenges on how to adopt efficient KM methods to achieve a better result.

An and Ahmad (2010) and Blackler (2002) both argued that most happenstances of the application of $\mathrm{KM}$ in the construction organization are problems of environmental factors such as cultural diversities of the construction workers, appropriate rules/regulation for the workers, complexity of the business, lack of suitable organizational strategy, lack of accepted 
organization information, etc. During the research work, most organization's are yet to identify the major effect of environmental factors of knowledge management and large percentage of the construction organizations are yet to realize how these environmental factors can hinder the implementations of KM. Moreover, during the study the major factors identified to KM implementation and adoptions are lacked of suitable information technology, lack of values, lack of accepted organizational strategy, improper organization leadership, organization information, organizational culture, lack of time by organization staff, cost in implementing KM, etc. Courage is required by researchers to identify the factors hindering the implementation of KM in the construction organization in Nigerian. Thus, the research on knowledge management is still minimum. The study invent a process to encourage and boost the participation of knowledge workers in the knowledge management by identifying some factors affecting the implementation of KM. Some environmental factors are identified with the model to represent, provide guidelines for $\mathrm{KM}$ adoption, implementation and understanding better KM in the Nigerian construction organization.

\section{Review of Literature}

\subsection{Organizational Culture}

One of the important obstacles to effective management of knowledge in organization is culture. Modeling culture is the focus in any organization, to manage its knowledge efficiently and more effectively (Chen \& Xu, 2010; Håkansson \& Waluszewski, 2014). Lack of interaction between construction workers is detriment to creative process in construction environment (Hartnell et al., 2011). Cultural interchanges between groups or individual are often the basis for inventing modern creative ideas and creating modern knowledge within organization, which can be observed as a likelihood of increasing knowledge management process (creating, sharing, acquisition, etc) (Hayton \& Cacciotti, 2014; Hislop, 2013). Construction worker's interaction should be motivated, both officially and casually, so that associations, perspectives; contacts are shared with one another (Hsu, 2008). Collaboration and Interaction are very crucial in an attempt to communicate unvoiced knowledge between groups or individual or change unvoiced ideas into explicit learning, thereby transmuting it from personal level to organizational level (Huber, 2001; Ibrahim \& Paulson, 2008). Thus, construction workers should possess the aptitude to self-establish their own learning and ideas in facilitating solutions to new or prevailing problems to produce or transfer knowledge (Hartnell et al., 2011).

Moreover, different researchers are of view that corporate vision is an important component of culture (Jain et al., 2015). Vision that pervades the organization people with the desirable sense of purpose that exceeds unremarkable happenings (Jiacheng et al., 2010). The general hallucination is envisioned to make a clear organizational drive and prompt the essential vicissitudes in the construction organization so that desire's goals can be achieved (Kalling, 2003). With the aid of spoken and interconnected vision, it is crucial to produce a sense of participation and influence among the construction workers (Kazi, 2005). In general, emphasis in hallucination declaration and value system be positioned on the constituent of the organization that inspires effective occurrence of the knowledge management process. 


\subsection{Organization Strategy}

Organization strategy is crucial in influencing innovative concepts and ideas. In rationalizing personal purposes or components within an organization, strategy often had the inadvertent consequences of hindering association in sharing, creating an acquisition of knowledge through the organizational boundary. The optimization of knowledge creation, sharing and acquisition within the organizational, functional expanse, can many times subs enhance the acquisition, creation and sharing across the organization (King et al., 2008). In a larger level, the enhancement of the knowledge management process within the organization can sub, optimized the process of knowledge management across a supply chain. In reality, it is crucial that construction organization strategy be designed for flexibility, so that they inspire acquisition, creating, sharing and collaboration within the organization boundaries and across a supply chain (Nonaka et al., 2005). With policy and process, incentives and rewards in any organization system can determine the channel from which acquisition, creating and sharing of knowledge is accessed (Pollack, 2012). These systems can generate barricades for effective and efficient knowledge management process. Incentive system should be introduced to encourage staffs are driven and rephrased for generating and sharing new ideas, learning outside their tasks and divisions.

\subsection{Organization Management and Leadership}

Top management and leadership commitment is highly recognized by knowledge management researchers. The two act as a aristocracy in providing foremost instance of knowledge aqcuisition, knowledge creation and knowledge sharing in the construction organization, pinpointing some precise barricades to knowledge management process and sending messages through the organization about the importance of knowledge management (Pemsel \& Müller, 2012). Leadership style funds and support the activities of knowledge management, appreciate individual, staff's effort and attainment in the implementation of knowledge management, positively pass across necessity for enhancing, fostering and care for effective process of knowledge management (Rai, 2011). If organization top management pays more attention in sensitizing the importance of knowledge management to the further enhancement of the organization, workers and individual will start to put consideration in the management of knowledge in the organization.

\subsection{Organization Information}

Individual or organization, collective memory is the cerebral assets and knowledge, capability of the organization. It reserves customs, morals, behavior, ethical standard and mental map for a certain period of time which can be vanished as new staffs come and goes (Reich et al., 2012). Personal memories are developed through skills, surveillance, practices and action while organization information are shaping knowledge deposited and disseminated through different holding amenities such as transformation, values, stories of passed construction event and the latest development, culture, all can be recovered, prospered and brought to bear in present decision (Rikowski, 2007). 


\subsection{Organizational Rules and Regulation}

The rules and regulation of any organizational are profoundly societal activities, which distress knowledge acquisition, creation, sharing and knowledge reuse in the construction organization. However, letdown to a treatise the construction organizational guidelines and regulation may hamper the effective knowledge management process in the industry (Rowley, 2008). Some of the leading rule and regulation identify by some notable scholars encompasses lawful assertion of workers of knowledge management, information reservation for employees, health and safety rules for the construction organization, and privacy for the knowledge workers. Thus, also recognized regulation and rules included unseen know-how in individual patterns of learning and creating knowledge, idiomatic dialects, sentiments and monotonous such as evasion can frustrate knowledge creation, acquisition and sharing within the construction organization (Saeed et al., 2010).

\section{Methodology}

Structural equation model was adopted to test the index of the environmental factors of knowledge management from the hypothesized model. The study involves multivariate method analysis to explore the relationship and covariance in the measurement model among the constructs and variables used. Exploratory factor analysis (EFA) was adopted to see the initial factor loading of the study variables, so all factors that loaded $\leq 4.99$ were not considered for further analysis as suggested by (Stevens, 2012). Regression analysis, path analysis and confirmatory factor analysis (CFA) were used. The result of EFA shows that all the construct/variables were statistically significant of Kaiser-Meyer Okin and Bartlet's test $(\mathrm{KMO})$ at $<.001$. However, confirmatory factor analysis was conducted to the rest seventeen variables. Three variables were deleted during re-specification of the model to achieve a reasonable model fit.

A stratified random sampling procedure was adopted to obtain 245 valid questionnaires from 300 questionnaires distributed to various qualified in the construction industry in Nigeria. The questionnaires were distributed among eighteen construction organization, making the total questionnaires used for the analysis to be $81 \%$. $22.7 \%$ of the respondents are qualified members of Nigerian Institutes of Architectures; $23.3 \%$ are qualified members of Council of Registered Engineers of Nigeria; the Nigeria Institute of Quantity surveyors and National Institute of Building had $18.6 \%$ and $14.8 \%$ respectively while other professionals are $1.6 \%$. 


\section{Macrothink}

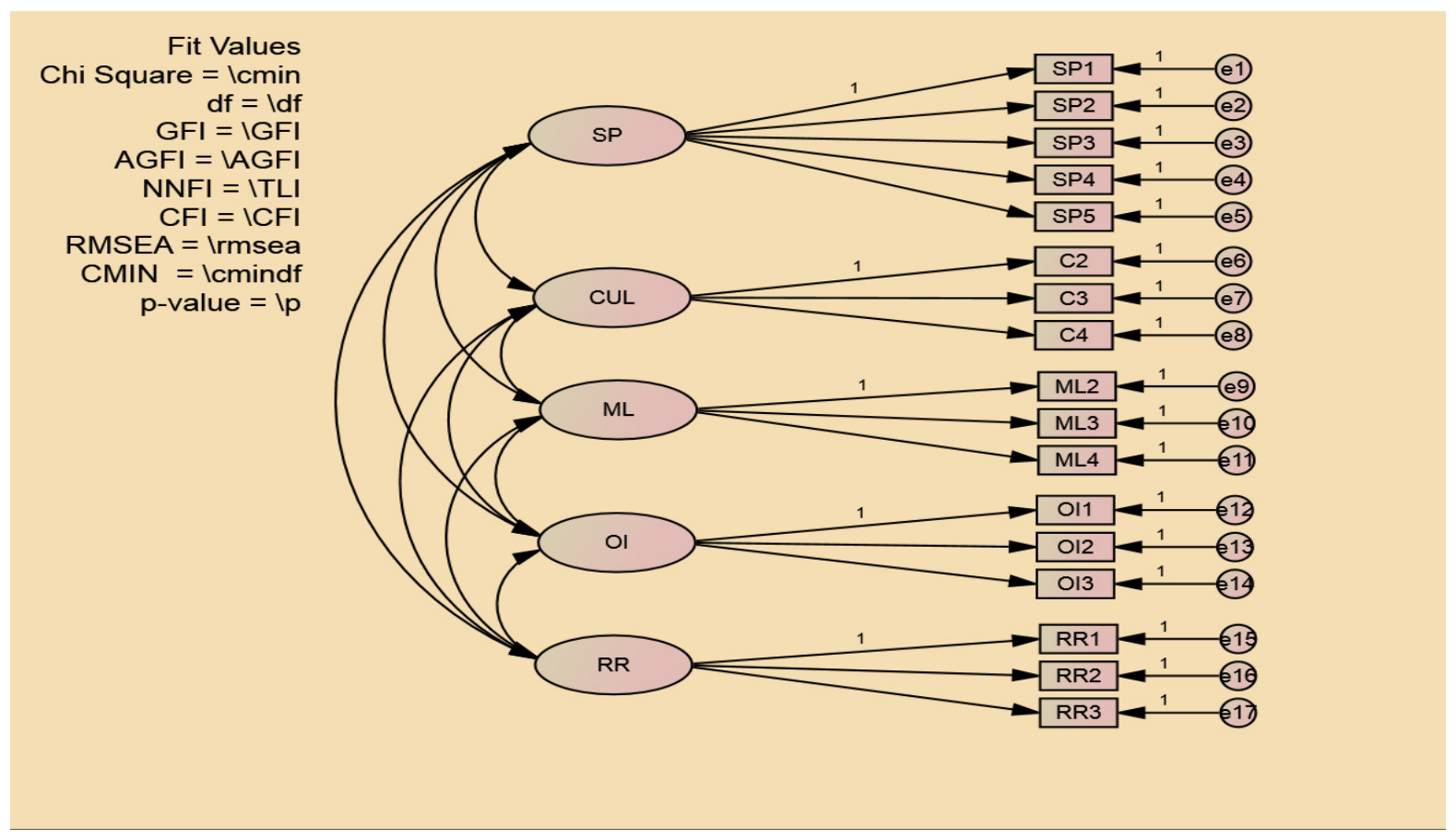

Figure 1. Hypothesized Measurement Model of the Environmental factors

$\mathrm{SP}=$ strategy/product, $\mathrm{ML}=$ management leadership, $\mathrm{OI}=$ organization information, $\mathrm{CUL}=$ culture and $\mathrm{RR}=$ rules/regulation

\section{Data Analysis}

During the data analysis, normality and outliner, assessments were used for missing values through data screening. SPSS version 22 shows that only one variable had a missing data and mean substitution method was used because the number is small as suggested by (Andrew, 2013; Arbuckle, 2007). Thus, skew ness and kurtosis test with leaf plots was adopted to determine the normality distribution during the substation method of missing data. Virtually, all the variables lie between -438 and 0.58 for skew ness and $-1.740-0.19$ for kurtosis which is within the recommended values of \pm 2 (skweness) and \pm 7 (kurtosis) by (Cohen, 2013; Davčik, 2013). Total estimate of kurtosis of the constructs is 47.596, which are also within the recommended values of $<50$ in an absolute world by (Duncan et al., 2013; Field, 2013). Discriminant validity was evaluated based on the suggestion by various researchers that, the measurement model should be free from redundant items in the model in terms of modification indices (MI) (Gelman \& Hill, 2006; Pearl, 2012).

\subsection{Results}

Unidimensinality of the model is achieved by deleting all factor loading $<0.6$ and convergent validity of the model is achieved using Average Variance Extracted (AVE) for every construct to be $\geq 0.5$ as recommended by different researchers (Teo, 2010; Weaver \& Maxwell, 2014) shown in Table 1 below. Composite reliability (CR) and internal consistency of the model were assessed and achieved with $\mathrm{CR} \geq 0.6$ as suggested by (Zainudin, 2014). Modification indices (MI) and standardized residual values were examined in conducting model 


\section{Al Macrothink}

Journal of Social Science Studies

ISSN 2329-9150

2016, Vol. 3, No. 1

technique's re-specification. Four variables were deleted, one indicator each from culture (C1), management leadership (ML1), organization information (OI4) and rules/regulation (RR4). Version 22.0 of AMOS ( analysis of moment structure) was used to test model prudent. Each of the variables in respective hypothesized model loaded $\geq 0.6$ as recommended by (Byrne, 2013b). Since the model acknowledges the data significantly, and MI was all less than fifteen in absolute figure as suggested by (Byrne, 2013a). Internal reliability and consistency of the data were assessed using Cronbach's alpha coefficient, which shows 0.82 , $0.919,0.85,0.79$, and 0.86 for culture, strategy and product, organization information, management leadership, and rules/regulation respectively. However, convergent validity of the model was achieved when all the items in the measurement model are statistically significant. Internal reliability shows how dependable the measuring model in measuring the intend constructs as all the Cronbach's Alpha values calculated are all above $\geq 0.7$ recommended by various researchers (Raedeke et al., 2013).

Table 1. Measurement of Variance Analysis, Validity and Composite Reliability of measurement model.

\begin{tabular}{|c|c|c|c|c|c|c|}
\hline Construct & Indicators & $\begin{array}{l}\text { Loadings } \\
\text { of factors }\end{array}$ & $\begin{array}{l}\text { Cronbach's } \\
\text { Alpha }\end{array}$ & $\begin{array}{l}\text { Average } \\
\text { variance }\end{array}$ & $\begin{array}{l}\text { Composite } \\
\text { reliability }\end{array}$ & $\begin{array}{l}\text { T- } \\
\text { value }\end{array}$ \\
\hline \multirow{5}{*}{$\begin{array}{l}\text { Strategy and } \\
\text { planning }\end{array}$} & SP1 & 0.94 & \multirow{5}{*}{0.919} & \multirow{5}{*}{0.694} & \multirow{5}{*}{0.720} & \\
\hline & SP2 & 0.79 & & & & 18.444 \\
\hline & SP3 & 0.87 & & & & 22.894 \\
\hline & SP4 & 0.74 & & & & 16.493 \\
\hline & SP5 & 0.84 & & & & 21.403 \\
\hline \multirow{4}{*}{ Culture } & $\mathrm{C} 1$ & Deleted & \multirow{4}{*}{0.82} & \multirow{4}{*}{0.614} & \multirow{4}{*}{0.675} & \\
\hline & $\mathrm{C} 2$ & 0.78 & & & & \\
\hline & $\mathrm{C} 3$ & 0.78 & & & & 12.078 \\
\hline & $\mathrm{C} 4$ & 0.79 & & & & 12.101 \\
\hline \multirow{4}{*}{$\begin{array}{l}\text { Management } \\
\text { Leadership }\end{array}$} & ML1 & Deleted & \multirow{4}{*}{0.79} & \multirow{4}{*}{0.775} & \multirow{4}{*}{0.754} & \\
\hline & ML2 & 0.76 & & & & \\
\hline & ML3 & 0.98 & & & & 10.548 \\
\hline & ML4 & 0.86 & & & & 9.921 \\
\hline \multirow{4}{*}{$\begin{array}{l}\text { Organization } \\
\text { Information }\end{array}$} & OI1 & 0.82 & \multirow{4}{*}{0.85} & \multirow{4}{*}{0.662} & \multirow{4}{*}{0.784} & \\
\hline & $\mathrm{OI} 2$ & 0.79 & & & & \\
\hline & $\mathrm{OI} 3$ & 0.83 & & & & 13.956 \\
\hline & OI4 & Deleted & & & & 15.328 \\
\hline \multirow{4}{*}{$\begin{array}{l}\text { Rules and } \\
\text { regulation }\end{array}$} & RR1 & 0.74 & \multirow{4}{*}{0.86} & \multirow{4}{*}{0.671} & \multirow{4}{*}{0.705} & \\
\hline & $\mathrm{RR} 2$ & 0.82 & & & & 13.100 \\
\hline & RR3 & 0.89 & & & & 13.424 \\
\hline & RR4 & Deleted & & & & \\
\hline
\end{tabular}




\section{Macrothink}

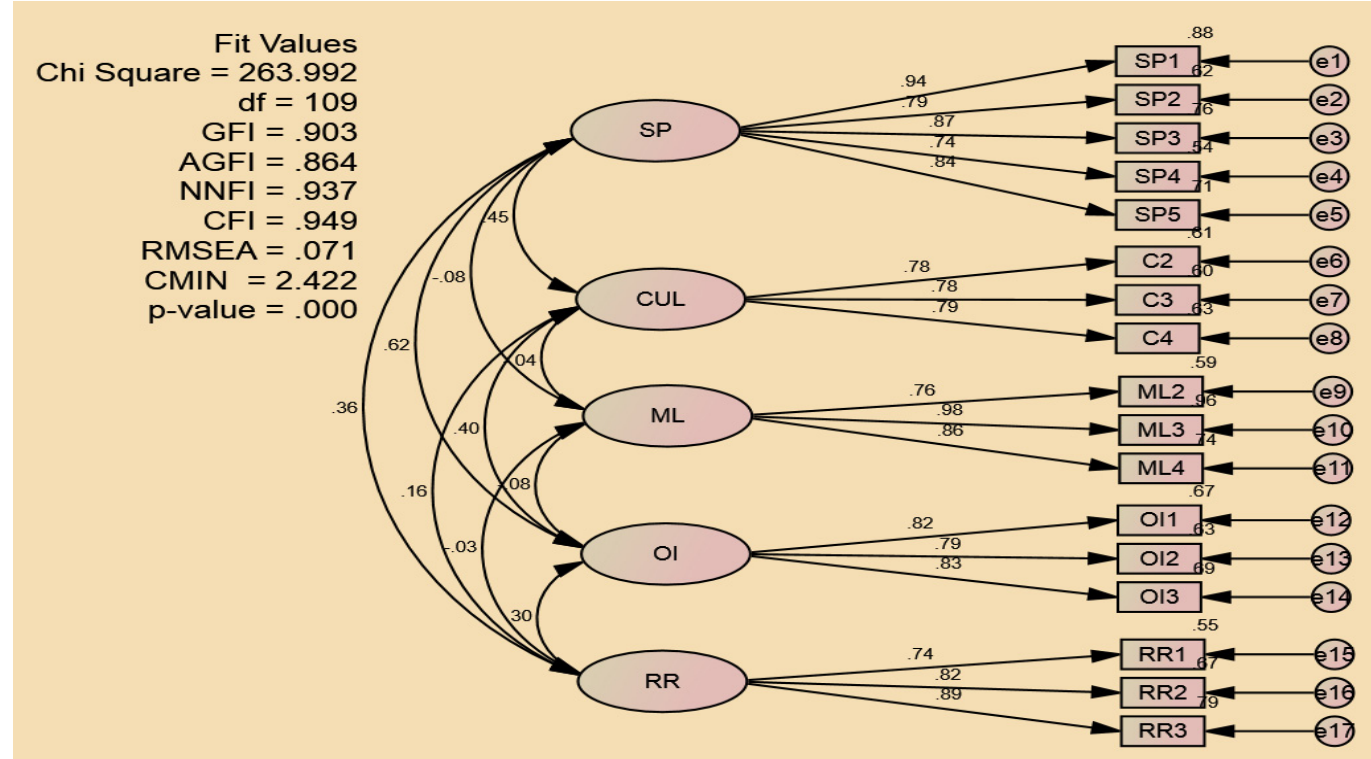

Figure 2. Confirmatory factor Analysis for Environmental Factors

$\mathrm{SP}=$ strategy/product, $\mathrm{ML}=$ management leadership, $\mathrm{OI}=$ organization information, $\mathrm{CUL}=$ culture and $\mathrm{RR}=$ rules/regulation

In analyzing the outcome of the hypotheses' model, different model fitting was adopted as presented in Figure 2. Using path analysis with a maximum likelihood estimates the result shows that acceptable goodness of fit was achieved with $\mathrm{GFI}=.903$, $\mathrm{AGFI}=.864, \mathrm{CFI}=.949$, $\mathrm{NNFI}=.937$ all within the recommended threshold of $>.80<1$ as suggested by (Hair et al., 2012; Stevens, 2012), the $\mathrm{p}$ - value $=.0001$, $\mathrm{RMSEA}=.0 .71, \mathrm{CMIN}=2.422$ all within the range recommended by various researchers (Bollen, 1989; Browne et al., 1993; Hipp \& Bollen, 2003; Kenny, 2011).

\subsection{Regression Analysis}

In supporting the convergent relationship between all constructs and variable, regression analysis was used to predict the strength of the determinant in the phenomenon, as all the Beta estimates are all $<1$ in absolute value. Moreover, all the multivariate values of the variables are considered significant at $<0.001$. 


\section{Macrothink}

Table 2. Standardized regression weights

\begin{tabular}{lllll}
\hline Factors/Variables & & & Beta Estimate & p-value \\
\hline SP1 & $<---$ & SP & .937 & $* * *$ \\
SP2 & $<---$ & SP & .789 & $* * *$ \\
SP3 & $<---$ & SP & .869 & $* * *$ \\
SP4 & $<---$ & SP & .738 & $* * *$ \\
SP5 & $<---$ & SP & .844 & $* * *$ \\
C2 & $<---$ & CUL & .778 & $* * *$ \\
C3 & $<---$ & CUL & .777 & $* * *$ \\
C4 & $<---$ & CUL & .792 & $* * *$ \\
ML2 & $<---$ & ML & .765 & $* * *$ \\
ML3 & $<---$ & ML & .982 & $* * *$ \\
ML4 & $<---$ & ML & .859 & $* * *$ \\
OI1 & $<---$ & OI & .819 & $* * *$ \\
OI2 & $<---$ & OI & .791 & $* * *$ \\
OI3 & $<---$ & OI & .830 & $* * *$ \\
RR1 & $<---$ & RR & .743 & $* * *$ \\
RR2 & $<---$ & RR & .818 & $* * *$ \\
RR3 & $<---$ & RR & .887 & $* * *$ \\
\hline & & & & \\
\hline
\end{tabular}

\subsection{Discussion}

In construction organization, management of available resources (knowledge) is presently enticing a considerable attention. In fact, most of the construction engineers and workers in most developing countries lack the courage in adopting and implementing knowledge management, while some lack the experiences in identifying the environmental factors of knowledge management. The study proposed and tested a model for adoption and implementation of environmental factors. The model consisted of five construct measurement; strategy and product, culture, management leadership, organization information and rules/regulation. From the analysis result, virtually all the variables, measure strategy and product loaded above $\geq 0.7$, whereas culture (C1) did not measure it. Management leadership was measured with four variable, but ML1 did not measure the construct, organization information and rules/regulation, on the other hand, were measured with three indicators each.

\section{Conclusion}

The aim of the study is to develop a KM environmental factor's model for adoption and implementation in context of the developing county such as Nigeria. The model exhibited a degree honesty and acceptability as demonstrated in the structural equation model statistical indices and can equally be carefully adapted for application in any developing country or elsewhere. This model can be adopted by academician and researcher in the construction 
organization from the developing country to increase awareness of efficiency and efficacy of the knowledge management setbacks. Project managers and knowledge managers in the organization can use and adopt the model as a guide to uplift and enhance the organizational performance. Construction companies have to manage their knowledge assets better if they want to survive in the competitive business world, especially in a developing country like Nigeria. Many construction organizations are still yet to comprehend the impending benefits of $\mathrm{KM}$ process to contest against foreign companies in our environment. So, distinguishing the barriers of environmental factors in enhancing the KM process will go a long way to improve the organization performance. The Government should upkeep the construction organization by engendering promising environment for the worker and business people to hold specialists and engineers to coach other workers within the organization in order to advance the awareness of knowledge management in the construction products in terms of quality, time and cost. The model was thrifty but can be threatened from other limitations; so distinct study from various locations with distinctive data collection is needed to improve the steadiness and levelheaded ness of the model.

\section{References}

Ahern, T., Leavy, B., \& Byrne, P. (2014). Knowledge formation and learning in the management of projects: A problem solving perspective. International Journal of Project Management. http://dx.doi.org/10.1016/j.ijproman.2013.06.007

Al-Gahtani, K., \& Ghani, S. R. (2010). Knowledge management tools: adaption in construction management practices. Proceedings of the 2010 Engineering Systems Management and Its Applications (ICESMA), 2010 Second International Conference on: IEEE, $1-6$.

Alekseev, A. (2010). Knowledge Management in Project-Based Organisations: The Success Criteria and Best Practises.

Amini, B., Ibrahim, R., Othman, M. S., \& Selamat, A. (2014). Capturing scholar's knowledge from heterogeneous resources for profiling in recommender systems. Expert Systems with Applications, 41(17), 7945-7957 http://dx.doi.org/10.1016/j.eswa.2014.06.039

An, M., \& Ahmad, H. S. (2010). Knowledge Management in Construction Projects: A Way Forward in Dealing with Tacit Knowledge. International Journal of Information Technology Project Management (IJITPM), 1(2), 16-42. http://dx.doi.org/10.4018/jitpm.2010040102

Andrew, M. (2013). Introduction to Statistics and SPSS in Psychology. Pearson Education.

Arbuckle, J. (2007). AmosTM 16 user's guide. Chicago: SPSS.

Blackler, F. (2002). Knowledge, knowledge work and organizations. The strategic management of intellectual capital and organizational knowledge. 47-64.

Bollen, K. A. (1989). A new incremental fit index for general structural equation models. Sociological Methods \& Research, 303-316. http://dx.doi.org/10.1177/0049124189017003004 
Bosch-Sijtsema, P. M., \& Henriksson, L.-H. (2014). Managing projects with distributed and embedded knowledge through interactions. International Journal of Project Management. http://dx.doi.org/10.1016/j.ijproman.2014.02.005

Browne, M. W., Cudeck, R., \& Bollen, K. A. (1993). Alternative ways of assessing model fit. Sage Focus Editions, 154, 136-136.

Byrne, B. M. (2013a). Structural equation modeling with AMOS: Basic concepts, applications, and programming. Routledge.

Byrne, B. M. (2013b). Structural equation modeling with LISREL, PRELIS, and SIMPLIS: Basic concepts, applications, and programming. Psychology Press.

Chen, Z., \& Xu, X. (2010). Study on Construction of Knowledge Management System Based on Enhancing Core Competence of Industrial Clusters. International Journal of Business and Management, 5(3), 217.

Cohen, J. (2013). Statistical power analysis for the behavioral sciences. Routledge Academic.

Davčik, N. S. (2013). The Use and Misuse of Structural Equation Modeling In Management Research. Working Paper-Working Paper-13/07 Instituti Universitario de Lisboa.

Duncan, T. E., Duncan, S. C., \& Strycker, L. A. (2013). An introduction to latent variable growth curve modeling: Concepts, issues, and application. Routledge Academic.

Egbu, C. O. (2004). Managing knowledge and intellectual capital for improved organizational innovations in the construction industry: an examination of critical success factors. Engineering, Construction and Architectural Management, 11(5), 301-315 http://dx.doi.org/10.1108/09699980410558494

Field, A. (2013). Discovering statistics using IBM SPSS statistics. Sage.

Gelman, A., \& Hill, J. (2006). Data analysis using regression and multilevel/hierarchical models. Cambridge University Press. http://dx.doi.org/10.1017/cbo9780511790942

Hair, J. F., Sarstedt, M., Pieper, T. M., \& Ringle, C. M. (2012). The use of partial least squares structural equation modeling in strategic management research: A review of past practices and recommendations for future applications. Long Range Planning, 45(5), 320-340. http://dx.doi.org/10.1016/j.lrp.2012.09.008

Håkansson, H., \& Waluszewski, A. (2014). Knowledge and innovation in business and industry: The importance of using others. Routledge.

Hartnell, C. A., Ou, A. Y., \& Kinicki, A. (2011). Organizational culture and organizational effectiveness: a meta-analytic investigation of the competing values framework's theoretical suppositions. Journal of Applied Psychology, 96(4), 677. http://dx.doi.org/10.1037/a0021987

Hayton, J., \& Cacciotti, G. (2014). 8 culture and entrepreneurship: empirical evidence for direct and indirect effects. Handbook of Research On Entrepreneurship: What We Know and What We Need to Know. 147. 


\section{I Macrothink}

Journal of Social Science Studies

ISSN 2329-9150 2016, Vol. 3, No. 1

Hipp, J. R., \& Bollen, K. A. (2003). Model fit in structural equation models with censored, ordinal, and dichotomous variables: Testing vanishing tetrads. Sociological Methodology. 33(1), 267-305. http://dx.doi.org/10.1111/j.0081-1750.2003.00133.x

Hislop, D. (2013). Knowledge management in organizations: A critical introduction. Oxford University Press.

Hsu, I. C. (2008). Knowledge sharing practices as a facilitating factor for improving organizational performance through human capital: A preliminary test. Expert Systems with Applications, 35(3), 1316-1326. http://dx.doi.org/10.1016/j.eswa.2007.08.012

Huber, G. P. (2001). Transfer of knowledge in knowledge management systems: unexplored issues and suggested studies. European Journal of Information Systems, 10(2), 72-79. http://dx.doi.org/10.1057/palgrave.ejis.3000399

Ibrahim, R., \& Paulson, B. C. (2008). Discontinuity in organisations: identifying business environments affecting efficiency of knowledge flows in Product Lifecycle Management. International Journal of Product Lifecycle Management, 3(1), 21-36. http://dx.doi.org/10.1504/IJPLM.2008.019972

Jain, A. K., Moreno, A., Tuggle, F., \& Ribiere, V. (2015). Organizational learning, knowledge management practices and firm' $s$ performance: an empirical study of a heavy engineering firm in India. The Learning Organization, 22(1). http://dx.doi.org/10.1108/TLO-05-2013-0024

Jiacheng, W., Lu, L., \& Francesco, C. A. (2010). A cognitive model of intra-organizational knowledge-sharing motivations in the view of cross-culture. International Journal of Information Management, 30(3), 220-230. http://dx.doi.org/10.1016/j.ijinfomgt.2009.08.007

Kalling, T. (2003). Knowledge management and the occasional links with performance. $\begin{array}{llll}\text { Journal of knowledge management, } & 7(3),\end{array}$ http://dx.doi.org/10.1108/13673270310485631

Kazi, A. S. (2005). Knowledge management in the construction industry: A socio-technical perspective. IGI Global. http://dx.doi.org/10.4018/978-1-59140-360-9

Kenny, D. A. (2011). Measuring model fit. Retrieved November. 29, 2011.

King, W. R., Chung, T. R., \& Haney, M. H. (2008). Knowledge management and organizational learning. Omega, 36(2), 167-172. http://dx.doi.org/10.1016/j.omega.2006.07.004

Nonaka, I., Toyama, R., \& Konno, N. (2005). SECI, ba and leadership: a unified model of dynamic knowledge creation. Knowledge Management: Critical Perspectives on Business and Management, 2, 317.

Pearl, J. (2012). The causal foundations of structural equation modeling. DTIC Document.

Pemsel, S., \& Müller, R. (2012). The governance of knowledge in project-based organizations. International Journal of Project Management, 30(8), 865-876. 
http://dx.doi.org/10.1016/j.ijproman.2012.02.002

Pollack, J. (2012). Transferring knowledge about knowledge management: Implementation of a complex organisational change programme. International Journal of Project Management, 30(8), 877-886. http://dx.doi.org/10.1016/j.ijproman.2012.04.001

Raedeke, T. D., Arce, C., De Francisco, C., Seoane, G., \& Ferraces, M. J. (2013). The Construct Validity of the Spanish Version of the ABQ Using a Multi-Trait/Multi-Method $\begin{array}{llll}\text { Approach. } & \text { anales } & \text { de } & \text { 693-700. }\end{array}$ http://dx.doi.org/10.6018/analesps.29.3.175831

Rai, R. K. (2011). Knowledge management and organizational culture: A theoretical integrative framework. Journal of Knowledge Management, 15(5), 779-801. http://dx.doi.org/10.1108/13673271111174320

Reich, B. H., Gemino, A., \& Sauer, C. (2012). Knowledge management and project-based knowledge in it projects: A model and preliminary empirical results. International Journal of Project Management, 30(6), 663-674. http://dx.doi.org/10.1016/j.ijproman.2011.12.003

Rikowski, R. (2007). Knowledge management: Social, cultural and theoretical perspectives. Elsevier. http://dx.doi.org/10.1533/9781780631981

Rowley, J. E. (2008). Organizing knowledge: an introduction to managing access to information. Ashgate Publishing, Ltd.

Saeed, T., Tayyab, B., Anis-Ul-Haque, M., Ahmad, H. M., \& Chaudhry, A. U. (2010). Knowledge management practices: Role of organizational culture. Proceedings of ASBBS, 17(1), 1027-1036.

Stevens, J. P. (2012). Applied multivariate statistics for the social sciences. Routledge.

Surakratanasakul, B., \& Hamamoto, K. (2014). Conjugate of knowledge items between abstract and organization knowledge models. Proceedings of the 2014 Digital Information and Communication Technology and it's Applications (DICTAP), 2014 Fourth International Conference on: IEEE, 231-236. http://dx.doi.org/10.1109/DICTAP.2014.6821687

Teo, T. (2010). Structural equation modelling: A primer for music education researchers. Music Education Research, 12(1), 105-118. http://dx.doi.org/10.1080/14613800903568270

Tong, C., Tak, W. I. W., \& Wong, A. (2015). The impact of knowledge sharing on the relationship between organizational culture and job satisfaction: the perception of information communication and technology (ICT) practitioners in Hong Kong. International Journal of Human Resource Studies, 5(1), 19-47. http://dx.doi.org/10.5296/ijhrs.v5i1.6895

Valmohammadi, C., Ahmadi, M., Irani, Z., \& Irani, Z. (2015). The impact of knowledge management practices on organizational performance: A balanced scorecard approach. Journal of Enterprise Information Management, 28(1). http://dx.doi.org/10.1108/JEIM-09-2013-0066

Weaver, B., \& Maxwell, H. (2014). Exploratory factor analysis and reliability analysis with 


\section{Macrothink}

Journal of Social Science Studies

ISSN 2329-9150

2016, Vol. 3, No. 1

missing data: A simple method for SPSS users. The Quantitative Methods for Psychology, 10(2), 143-152.

Zainudin, A. (2014). A Handbook on SEM for Academicians and Practitioners. MPWS Training Center, Bander Baru Bangi, Selangor: MPWS Rich Resources.

\section{Copyright Disclaimer}

Copyright reserved by the author(s).

This article is an open-access article distributed under the terms and conditions of the Creative Commons Attribution license (http://creativecommons.org/licenses/by/3.0/). 